\title{
Dependence of Chlorophyll Content in Leaves from The Light Regime, Electromagnetic Fields and Plant Species
}

\author{
Alexander Kholmanskiy* and Nataliya Zaytseva \\ Department of Scientific Center, Moscow State University of Medicine and Dentistry, Russia
}

Submission: November 20, 2019; Published: July 13, 2020

"Corresponding author: Alexander Kholmanskiy, Department of Scientific Center, A I Yevdokimov Moscow State University of Medicine and Dentistry, Russia

\begin{abstract}
The regularity of the distribution of chlorophylls content in a series of 30 cultivated plants and 75 steppe grasses was studied. The increased content of chlorophyll and magnesium in vegetables and grains compared with greens and steppe grasses is associated with more complex genetics of metabolism, which has stages of flowering and fruiting. The chlorophyll content increases with the use of LED phytoirradiators with an emission band coinciding with the first absorption band of chlorophyll. Industrial electromagnetic fields can affect the biosynthesis of pigments in deciduous trees, but cultivated herbaceous plants are not sensitive to them.

Keywords: Content; Chlorophyll; Magnesium; Phytoirradiators; Vegetables; Grains; Grass
\end{abstract}

\section{Introduction}

The productivity of photosynthesis of green plants is determined mainly by their genetics and strongly depends on temperature, nutrient medium and light regime Polevoj [25]; Andrianova \& Tarchevskij [2]. These factors determine the structure and efficiency of the Photosynthetic Apparatus of the plant (PSA). The key functional elements of PSA are $a$ and $b$ forms of the Chlorophyll (Chl) Senge [28]; Kholmanskiy \& Smirnov [16] and water, which plays the role of a dynamic matrix and active metabolite Polevoj [25]; Kholmanskiy \& Tilov [13]; Aksenov [1]. Water sensitizes PSA by forming complexes with Mg and chiral centers Chl Kholmanskiy \& Smirnov [16] and other molecules in the composition of PSA Senge [28]; Kholmanskiy [14]; Kholmanskiy [15]; Zaytseva \& Sitanskaya [37]. The abnormal thermodynamic properties of water optimize the physics of cold stratification of seeds at a temperature of about $4^{\circ} \mathrm{C}$ Kholmanskiy [15] and minimize the energy of seed germination and photosynthesis in the temperature range $15-25^{\circ} \mathrm{C}$ Polevoj [25]; Kholmanskiy [15]. The photo- and thermophysics of Chl substantially depend on the $\mathrm{Mg}$ ion in the center of porphyrin cycle and the electronic nature of substituents in it Senge [28]; Kholmanskiy \& Smirnov [16]. In principle, chlorophyll can play the role of a marker of the total $\mathrm{Mg}$ content in a plant and therefore can be considered an adequate characteristic of the nutritional value of a plant product.
The photochemistry and photo physics of PSA are determined primarily by the electronic structure of the ground and excited electronic states of Chl. A significant difference in the biophysics of chlorophyll Chl a and Chl b Tyutereva \& Ivanova [35] is caused by the replacement of the $\mathrm{CH} 3$ group by the electron-acceptor and proton donor groups of $\mathrm{CHO}$ in the 7 th position of pheophytin (Figure 1). In Frese [9]; Kholmanskiy \& Smirnov [16], the electronic nature of the ground and lower excited states of $\mathrm{Chl}$ was attributed to states with charge transfers whose dipoles are oriented along the mutually orthogonal $\mathrm{X}$ and $\mathrm{Y}$ axes of the Chl molecule. The high dipole moments of the excited states of Chls initiate electron and proton transfers from other PSA components and these reactions can accelerate the kinetics of photochemical reactions in PSA. It was suggested in Kholmanskiy [18] that micro polarization of PSA promotes proton diffusion in leaves and intensifies the extraction of micro and macro cell ions by a plant. Mg and Chl greatly increase the nutritional and medicinal value of cultivated plants, both leafy and fruit-bearing. In Kholmanskiy [17-18] it was established that the efficiency of Mg extraction by plant leaves of cultivated plants depends on their species and responds to changes in the irradiation spectrum. It can be assumed that a similar dependence should be observed for the content of $\mathrm{Chl}$ in plant leaves. To deepen understanding of the biophysical relationship between 
plant productivity and $\mathrm{Chl}$ we compared the total content of $\mathrm{a}+\mathrm{b}$ $\mathrm{Chl}$ and $\mathrm{Mg}$ in raw samples of leaves of a number of cultivated plants and steppe grasses. We analyzed the dependence of the Chl content in the leaves of cultivated plants on the light regime, and also compared the effects on photosynthesis of $\mathrm{Chl}$ a and $\mathrm{Chl}$ $\mathrm{b}$ in plantain and wheat seedlings of an electromagnetic industrial Novichkova \& Podkovkin [23]; Shashurin [27] and an electrostatic vortex field Therapeutic reel Mishina [33].

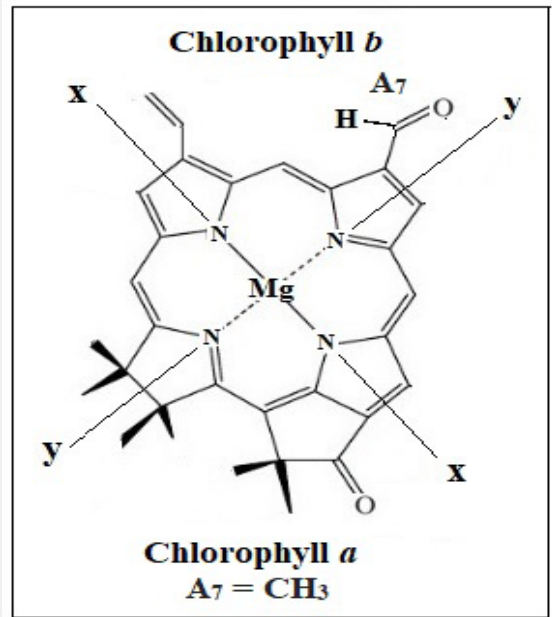

Figure 1: Structures of the porphyrin cores of Chlb and Chla.

\section{Results and discussion}

The empirical data on the content of chlorophylls $a$ and $b$ in cultivated plants and grasses were taken from books and works published by us and other authors. Table 1 shows the total content of $\mathrm{Chl} \mathrm{a}+\mathrm{b}$ (hereinafter [Chl]) and the ratio $\mathrm{a} / \mathrm{b}$ for raw samples of plant leaves. The determination of [Chl] in the works was carried out according to the methods described in Lichtenthaler \& Buschmann [21]. In Bohn [3] [Chl] was determined using liquid chromatography, and the $\mathrm{Mg}$ content in $\mathrm{Chl}$ was calculated based on its mass fraction of $\sim 2.7 \%$ in a and $b$ Chl. In this work, we compared the concentrations of total $\mathrm{Mg}$ and $\mathrm{Mg}$ in the composition of Chl (Table 2).

Table 1: The content of chlorophyll $a$ and $b$ in the leaves of different plants.

\begin{tabular}{|c|c|c|c|c|c|}
\hline \multirow[t]{2}{*}{ Sample } & $\begin{array}{l}\text { Time growth - week (w); irradiation } \\
\text { conditions - Mercury Lamp (ML); Sodi- } \\
\text { um Lamp (SL); LED; Sun }\end{array}$ & \multicolumn{3}{|c|}{ Chlorophyll (mg/g) } & \multirow{2}{*}{ Ref. } \\
\hline & & $a+b$ & $\mathrm{a} / \mathrm{b}$ & & \\
\hline \multirow{4}{*}{ Tomato } & $\begin{array}{l}5 \text { varieties } \\
\text { SL }\end{array}$ & \multicolumn{2}{|c|}{1.2} & 2.7 & Kavtsevich [11] \\
\hline & & \multirow[t]{2}{*}{1.4} & 1.3 & \multirow{3}{*}{$\begin{array}{c}\text { Smirnov } \\
\text { \& Khol- } \\
\text { manskiy, } \\
{[30]} \\
1.1 \\
1.5\end{array}$} & \\
\hline & LED1 & & & & \\
\hline & Sun & & & & \\
\hline \multirow{3}{*}{ Eggplant } & Extract in acetone & & & \multirow{3}{*}{-} & \multirow{3}{*}{ Mezhunts, [22] } \\
\hline & & \multicolumn{2}{|l|}{1.8} & & \\
\hline & & \multicolumn{2}{|l|}{1.8} & & \\
\hline
\end{tabular}




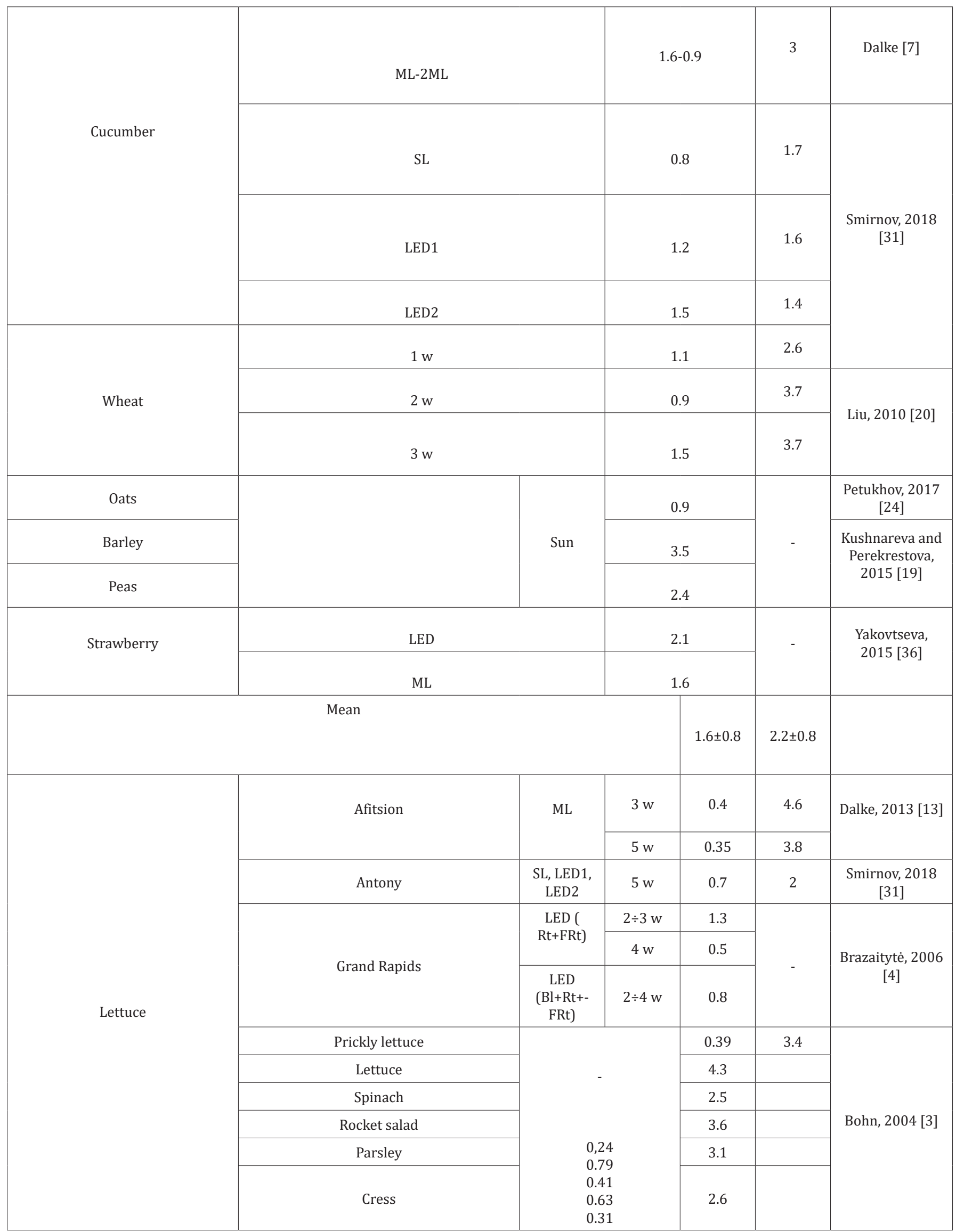




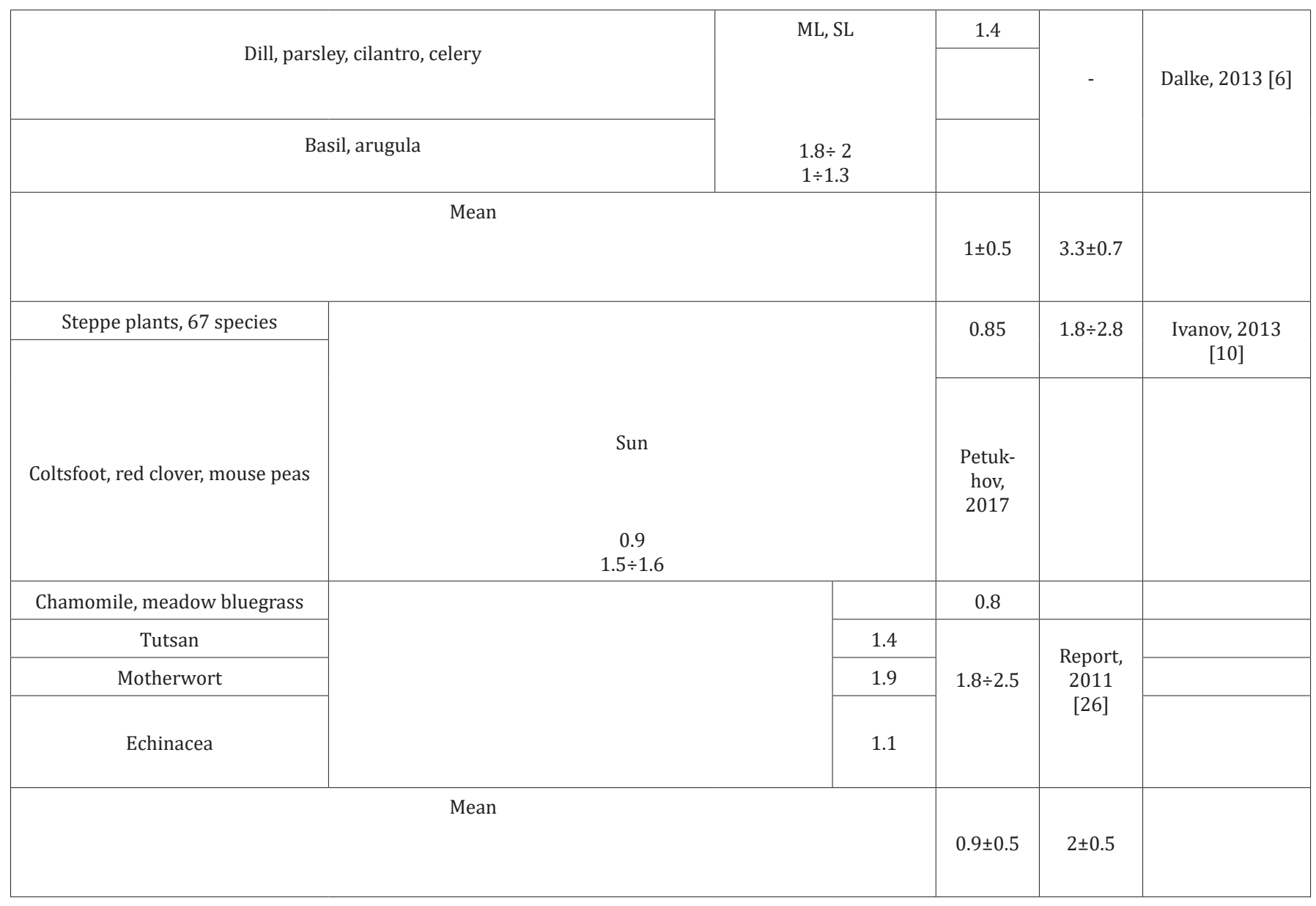

Table 2: The magnesium content in the raw leaf, fruit and chlorophyll.

\begin{tabular}{|c|c|c|c|c|c|}
\hline Sample (raw) & & $\operatorname{Mg}[8]$ & [Chl] & [Mg-Chl] & \multirow{2}{*}{$\mathrm{Mg} /[\mathrm{Mg}-\mathrm{Chl}]$} \\
\hline & \multicolumn{2}{|c|}{$\mathrm{mg} / \mathrm{g}$} & $\mu \mathrm{g} / \mathrm{g}$ & & \\
\hline Lettuce & \multirow{3}{*}{ Leave } & 0.14 & 0.7 & 20 & 7 \\
\hline \multirow{2}{*}{ Tomato } & & 1.1 & 1.5 & 40 & 28 \\
\hline & & 1.1 & 1.2 & 32 & 34 \\
\hline Cucumber & Fruit & 0.2 & 0.04 (Bohn, 2014 [3]) & 1 & 200 \\
\hline
\end{tabular}

A large scatter of [Chl] values in different works is caused by differences in both their measurement methods and the growing conditions of the same plants. The [Chl] values determined for dry samples were recalculated for the wet state using a drying coefficient $(\mathrm{k})$. It was evaluated by determining the weight of a fresh sample and after drying it at a temperature of no higher than $40^{\circ} \mathrm{C}$. For vegetable crops (tomato, cucumber), leaf (lettuce, greens) and steppe grasses their k were: 8.5; $15-20$ and 6-7, respectively. At the same time, the proportion of water in raw samples was determined by the ratio $(\mathrm{k}-1) / \mathrm{k}$ and was equal to: $88 \% ; 93-96 \%$ and $85-86 \%$, respectively.
The Table 1 shows [Chl] values for plants growing in natural and greenhouse conditions. In the latter case, the age of the samples (weeks) and the light regimes were varied. The irradiators included various combinations of Blue (Bl), Green (Gr), Red (Rt) Light Emitting Diodes (LED1 and LED2) Kholmanskiy [18] and 400W high pressure sodium (SL) and mercury (ML) lamp. Their emission spectra and the absorption spectrum of Chl are shown in Figure. In some works, the LED composition included a diode emitting in the far-red region of the spectrum (FRt) with a maximum at $730 \mathrm{~nm}$. Plant species in Table 1 are divided into three groups: vegetables, cereals, berries (I); lettuce and greens (II); grasses (III). The mean values of [Chl] in the II and III groups 
are close and 1.6 times less than in the I group. At the same time, [Chl-b] in the I-st III-th is 2 times less than [Chl-a], and in the II-th one 3.3 times. The value of [Chl] in the first and second groups of plants reaches a maximum at 3 weeks of growth and depends on the spectral composition and intensity of irradiation. The $\mathrm{Chl}$ content decreases when the irradiation intensity is exceeded by the norms of the optimal light regime Dalke [7]. Moreover, the Chl photo destruction reaction can contribute to the negative effect Kholmanskiy \& Smirnov [16]. The efficiencies of Chl biosynthesis in the leaves of plants of group I are close when the plants are irradiated with LED irradiators and the sun and are higher than when irradiated with SL. This result can be explained by the good overlap of the Rt emission bands of LED1 and LED2 with the first absorption band of $\mathrm{Chl}$ a and $\mathrm{b}$ (Figure 2). In group II, the dependence of the efficiency of Chl biosynthesis on the irradiation spectrum is less pronounced. Chl biosynthesis is limited by the efficiency of the plant's extraction of the $\mathrm{Mg}$, which depends on the type of plant and the irradiation spectrum Kholmanskiy [18]. Table 2 shows the total content of $\mathrm{Mg}$, Chl, and $\mathrm{Mg}$ in $\mathrm{Chl}$ ([Mg-Chl]) in the leaves and fruits of plants of the first and second groups, for samples grown under irradiation ML. From these values, the concentration ratio of total $\mathrm{Mg}$ to $\mathrm{Mg}$ in the composition of $\mathrm{Chl}$ $(\mathrm{Mg} /[\mathrm{Mg}-\mathrm{Chl}])$ was calculated.

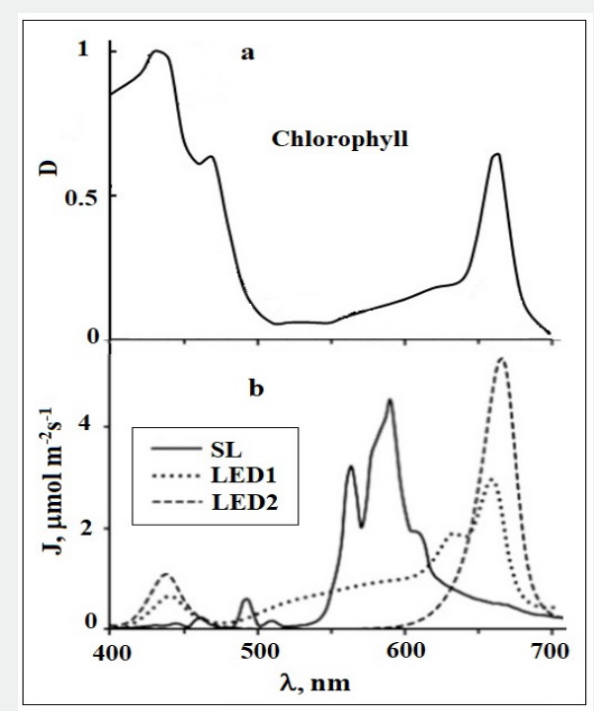

Figure 2: The absorption spectrum of a solution of $\mathrm{Chl}$ in ethanol (a) and the emission spectra of a sodium lamp (SL) and irradiators from two LED compositions, LED1 and LED2 (b). The initial spectra from Kholmanskiy \& Smirnov [16].

The obtained relations $\mathrm{Mg} /[\mathrm{Mg}-\mathrm{Chl}]$ indicate that the total $\mathrm{Mg}$ content in plants significantly exceeds [Chl], and this disproportion in plants of the $1^{\text {st }}$ group is $4-5$ times greater than in plants of the $2^{\text {nd }}$ group. This is due to the fact that $\mathrm{Mg}$ is included in the active center of the enzyme, providing assimilation of $\mathrm{CO} 2$ Polevoj [25] and also participates in the activation of many other complexes Senge [28]; Shkol'nik [29]; Sukovataya [32]. In addition, the genetics of cucumber and tomato, unlike lettuce, includes programs for the stages of flowering and fruiting with their specific biochemistry and bioenergy Shkol'nik [29]; Tikhomirov, Sharupich [34]. A significant contribution to the intensification of photosynthesis and enzymatic reactions in animal and plant organisms is made by the magnetic isotope $25 \mathrm{Mg}$ Buchachenko [5] the content of which in natural magnesium is $10 \%$. Apparently, $25 \mathrm{Mg}$ in the composition of enzymes plays an important role in the functioning of the phytochrome and cryptochrome PSA systems, activating magnetically sensitive dark reactions of radical ion pairs Evans [8]. Chl charge transfer states in dark reactions relax with the formation of long-lived excitons Frese [9]. Their participation in the work of PSA can, in principle, determine the dependence of the efficiency of photosynthesis on external electromagnetic and electric fields. To verify this assumption, we compared the dependence of the content of pigments - Chl a, $\mathrm{Chl} \mathrm{b}$ and carotenoids $(\mathrm{k})$ in maple leaves growing at a distance of 0 to $1000 \mathrm{~m}$ (control) from $110 \mathrm{kV}$ power lines Novichkova \& Podkovkin [23] and in the leaves of plantain seedlings, grown in an Electromagnetic Field (EMF) with a frequency of $50 \mathrm{Gz}$ and different intensities Shashurin [27], as well as wheat seedlings growing in an electrostatic vortex field with a frequency of $300 \mathrm{kGz}$ Therapeutic reel Mishina [33]. Recent experiments were carried out by us, using similar methods Kholmanskiy \& Smirnov [16]; Kholmanskiy [18]. The results and experimental conditions are shown in Table 3. The errors in measuring the pigment content in all samples were about $10 \%$. From the data of Table 3 it follows that the influence of EMF affects the efficiency of pigment biosynthesis only in a tree. The reason for this may be 
the elongation of transport communications along which charged mineral elements move from bottom to top, and phytohormones from top to bottom. The electrophysical properties of the sap in the layers of cambium and sapwood of deciduous trees, in contrast to the resin of conifers, contribute to electro tropism Kholmanskiy [12].

Table 3: Effect of electromagnetic fields on pigment photosynthesis.

\begin{tabular}{|c|c|c|c|c|c|c|c|}
\hline \multirow{3}{*}{ Sample (raw) } & \multirow{3}{*}{$\begin{array}{l}\text { Conditions of options. } \\
\text { Control conditions. }\end{array}$} & \multicolumn{4}{|c|}{ Chlorophyll and carotenoids (mg/g) } & & \\
\hline & & \multicolumn{3}{|c|}{ Options } & \multicolumn{3}{|c|}{ Control } \\
\hline & & $a+b$ & $\mathrm{a} / \mathrm{b}$ & $\mathrm{k}$ & $a+b$ & $\mathrm{a} / \mathrm{b}$ & $\mathrm{k}$ \\
\hline Wheat & Whirlwind electric field. Contr. - without field & 1.32 & 3 & 0.22 & 1.31 & 3 & 0.23 \\
\hline Plantain & $\begin{array}{l}\text { EM field } 50 \mathrm{Gz}(\mathrm{E}=230-1800 \mathrm{~V} / \mathrm{m} \text {; B=350-2000 nTs). } \\
\text { Contr. }(\mathrm{E}=12 \mathrm{~V} / \mathrm{m} ; \mathrm{B}=50 \mathrm{nTs})\end{array}$ & 0.81 & 1.7 & 0.66 & 0.84 & 1.6 & 0.62 \\
\hline Maple & $\begin{array}{c}\text { EM field power lines at } 0-230 \mathrm{~m} . \\
\mathrm{m}\end{array} \quad$ Contr. - at 1000 & 0.62 & 2.6 & 0.14 & 0.45 & 2.5 & 0.1 \\
\hline
\end{tabular}

\section{Conclusion}

Thus, it was found that the content of chlorophyll and magnesium in the leaves of cultivated plants is significantly higher in fruitful species than in leafy and, especially in steppe grasses. The chlorophyll content increases when growing plants in light regime using LED irradiators having a radiation band that overlaps well with the first absorption band of chlorophyll $a$ and $b$. Differences in the content of chlorophyll and plant productivity are associated with a more complex genetic program of metabolism in higher cultivated plants, including the stages of flowering and fruiting.

\section{References}

1. Aksenov SI (2004) Water and Its Role in the Regulation of Biological Processes. Izd RKhD: pp. 212.

2. Andrianova Ju E, Tarchevskij IA (2000) Chlorophyll and plant productivity. Moscow: Nauka: pp.135.

3. Bohn T (2004) Chlorophyll-bound Magnesium in Commonly Consumed Vegetables and Fruits: Relevance to Magnesium Nutrition. J Food Sci 69(9): 347-350.

4. Brazaitytė A (2006) Optimization of Lighting Spectrum for Photosynthetic System and Productivity of Lettuce by Using Lightemitting Diodes. Proc Vth IS on Artificial Lighting Ed R Moe Acta Hort: 711.

5. Buchachenko AL (2014) Magnetically dependent molecular and chemical processes in biochemistry, genetics and medicine. Russ Chem Rev 83(1): 1-12.

6. Dalke IV (2013) Efficiency of the use of light energy and productivity of the greenhouse culture of leaf lettuce. Proceed TSHA 5: 60-68.

7. Dalke IV (2014) Photosynthetic productivity and the efficiency of the use of light energy in the greenhouse culture of a cucumber when exposed to light inside the conenoses. Ibid 5: 13.

8. Evans EW (2013) Magnetic field effects in flavoproteins and related systems. Interface Focus 3(5).

9. Frese RN (2003) Electric Field Effects on the Chlorophylls, Pheophytins, and $\beta$-Carotenes in the Reaction Center of Photosystem II. Biochemistry 42(30): 9205-9213.
10. Ivanov LA (2013) Changes in the chlorophyll and carotenoid contents in the leaves of steppe plants along a latitudinal gradient in South Ural. Rus J Plant Physiology 60(6): 812-820.

11. Kavtsevich VN, Derevinsky AV (2015) Characterization of the pigment fund of the leaves of the lines of the tomato brush morphotype. West Vitebsk State University 1: 56-61.

12. Kholmanskiy AS (2009) Adaptation of plants to abnormal physical factors. Electron Math Med Biol J 8(3).

13. Kholmanskiy AS, Tilov AZ, Sorokina E Yu (2013) Drying Kinetics of Plant Products: Dependence on Chemical Composition. J Food Engineering 117: 378-382.

14. Kholmanskiy A (2016) Chirality anomalies of water solutions of saccharides. J Mol Liq 216: 683-687.

15. Kholmanskiy AS (2018) Activation of biosystems by an external chiral factor and a decrease in temperature. Asymmetry 12(3) 64-77.

16. Kholmanskiy AS, Smirnov AA, Parmon VN (2018) Bleaching of solutions of chlorophylls $a$ and $b$ with blue and red light. High Energy Chem 52(1): 6-13.

17. Kholmanskiy AS (2019) Dependence of extraction by cultural plants micro and macroelements from spectrum of phytoirradiators. Agrophysics 1: 52.

18. Kholmanskiy A (2019b) Modeling of extraction mechanism of mineral elements by plants. Current Plant Biology 19100104.

19. Kushnareva OP, Perekrestova EN (2015) The effect of various concentrations of copper and lead salts on the chlorophyll content and carbon content in plant leaves. Bul Orenburg SU 10(185): 194-197.

20. Liu D (2010) Influence of mercury on chlorophyll content in winter wheat and mercury bioaccumulation. Plant Soil Environ 56(3): 139143.

21. Lichtenthaler HK, Buschmann C (2001) Current Protocols in Food Analytical Chemistry. F4.3.1-F4.3.8.

22. Mezhunts M (2009) Application of dimethylsulfoxide as a solvent of photosynthetic pigments in field investigations. Bull State Agrarian Univ Armenia.

23. Novichkova EA, Podkovkin VG (2007) The effect of electromagnetic field of power lines $110 \mathrm{kV}$ to morphometric indicators and concentration of photosynthetic pigments in maple ash-leaved Acer negundo L. Vestn. SamSU - Natural Science Series 8(58): 173-180. 
24. Petukhov AS (2017) Assessment of the content of photosynthetic pigments in plants of different species under conditions of anthropogenic stress. Int Student Sci Bul 6.

25. Polevoj VV, Fiziologija rastenij, Moscow: Vysshaja shkola (1989): 464.

26. Report. “Gorno-Altai Botanical Garden”(2011) Central Siberian Botanical garden SB RAS.

27. Shashurin MM (2014) Response of medium plantain to the action of an electromagnetic field of industrial frequency $(50 \mathrm{~Hz})$. Plant Physiology 61(4): 517-521.

28. Senge MO (2014) Chlorophylls, Symmetry, Chirality, and Photosynthesis. Symmetry 6(3): 781-843.

29. Shkol'nik M Ja (1974) Trace elements in plant life] Leningrad: Nauka pp. 32.

30. Smirnov AA, Kholmanskiy AC (2017) Dependence of photosynthesis of pigments and productivity of tomato from the spectral composition of the radiator. Scientific Life 10: 14-19.
31. Smirnov A, (2018) Optimization of Lighting Spectrum of Greenhouse Vegetables by Using Light-Emitting Diodes. Int J Research in Pharmacy and Biosciences 5(4): 11-17

32. Sukovataya IE (2008) Photobiophysics. Krasnoyarsk. SFU 438.

33. Therapeutic reel Mishina: reviews and description.

34. Tikhomirov AA, Sharupich VP (2000) Light culture of plants: biophysical and biotechnological foundations. Novosibirsk 213.

35. Tyutereva EV, Ivanova AN, Wojciechowska OV (2014) On the role of chlorophyll b in ontogenetic adaptations of plants. Successes in modern biology 134(3): 249-256.

36. Yakovtseva MN, Govorova GF, Tarakanov IG (2015) Photomorphogenetic regulation of the growth and development of garden strawberries (Fragaria xananassa Duch.) in light culture. Proceed TSHA 3.

37. Zaytseva N, Sitanskaya I, Kholmanskiy A (2016) Temperature dependence of the optical activity of terpene and sugar solutions. Bulletin MSRU 1: 57-63. 